Bryant University

Bryant Digital Repository

5-3-2019

\title{
Mapping Policy Issues: A Simple, Active-Learning Exercise for Critical Thinking
}

Richard Holtzman

Bryant University, rholtzma@bryant.edu

Follow this and additional works at: https://digitalcommons.bryant.edu/histss_jou

Part of the Political History Commons, Scholarship of Teaching and Learning Commons, and the United States History Commons

\section{Recommended Citation}

Holtzman, Richard, "Mapping Policy Issues: A Simple, Active-Learning Exercise for Critical Thinking" (2019). History and Social Sciences Faculty Journal Articles. Paper 95.

https://digitalcommons.bryant.edu/histss_jou/95

This Article is brought to you for free and open access by the History and Social Sciences Faculty Publications and Research at Bryant Digital Repository. It has been accepted for inclusion in History and Social Sciences Faculty Journal Articles by an authorized administrator of Bryant Digital Repository. For more information, please contact dcommons@bryant.edu. 


\title{
Mapping Policy Issues:
}

\section{A Simple, Active-Learning Exercise for Critical Thinking \\ Richard Holtzman, Bryant University}

Richard Holtzman is associate professor of political science at Bryant University. He can be reached at rholtzma@bryant.edu.

\begin{abstract}
Many students in my undergraduate American politics courses struggle to see policy issues as complex. Too often, they get stuck making surface-level observations or jumping straight to personal opinions, falling far short of critical thinking. This article introduces an active-learning exercise - situational mapping — that provokes students to recognize and think critically about the complexities of policy issues such as immigration, abortion, campaign financing, and guns. Adapted from a grounded-theory research technique, the goals of this mapping exercise are to (1) help students see policy issues as messy, (2) encourage them to "wallow in complexity" rather than oversimplify, and (3) provoke them to think through complexities before forming conclusions. The learning exercise actively engages every student, is simple to prepare and implement, can be completed during a 50-minute class, and is flexible in its application. It also involves teamwork, informal presentations, moving around the classroom, and opportunities for creativity.
\end{abstract}


Policy issues are messy. As political scientists, we try to bring order to this complexity. As teachers, we help students to think through this messiness on their own. In my undergraduate American politics courses, many students struggle to see policy issues as complex. Too often, they get stuck making surface-level observations or jumping straight to personal opinions, falling far short of critical thinking.

Situational mapping is an active-learning exercise that provokes students to recognize and think critically about the complexities of policy issues. This exercise actively engages every student, is simple to prepare and implement, and can be completed during a 50-minute class. It is an example of what Lang (2016) called "small teaching"- that is, minor modifications to our courses that can have outsized impacts on learning.

Situational mapping was developed by Clarke $(2003,556)$ as a grounded-theory research technique that involves deep immersion in the "complications, messiness, and denseness of actual situations." The purpose of mapping "situations," which she defined as "arrangement[s] of relations among many different kinds and categories of elements" (Clarke, Friese, and Washburn 2018 , 17), is to provoke researchers to "analyze more deeply" (Clarke 2003, 560). It is tool for critical thinking.

Shifting from research to teaching, I adapted this technique to an exercise focused on a central component of critical thinking in political science: "taking into account the complexities of an issue" (American Association of Colleges \& Universities 2009). The exercise is guided by three learning objectives. The first is to help students recognize policy issues as messy. According to Keohane $(2009,360)$, "Great leaps forward in political science often take place when someone sees puzzles where others only have seen facts.” Thinking critically demands that 
students see complexity where they may have seen only competing political arguments for and against.

The second learning objective is to encourage students to "wallow in complexity" rather than oversimplify. This practice involves deliberately identifying a policy issue's key elements and exploring dynamic relationships among them. The third learning objective is to provoke students to think through complexities before forming conclusions about policy issues. Taking a position based on evidence is a central tenet of critical thinking.

I use situational mapping in my introductory course to explore policy issues such as immigration, abortion, campaign financing, and guns. It is sufficiently flexible to be used for other purposes as well, including unpacking political concepts, encouraging metacognitive reflection, and training in leadership skills. ${ }^{1}$ I regularly use the exercise in my 50-minute classes; however, the amount of time used to complete it is flexible because each step of the process can be extended easily. Mapping also involves features that promote active engagement in the classroom, including teamwork, informal presentations, physical movement, and opportunities for creativity.

The remainder of this article outlines the primary steps of the situational-mapping exercise and explains how each is implemented.

\section{Pre-Reading}

For mapping policy issues, students read an assigned CQ Researcher report before class. ${ }^{2}$ To increase assurance that students will read, they complete a "pre-discussion" assignment before class, which involves posting two evidence-based responses to questions on the coursemanagement website. ${ }^{3}$ These readings purposefully provide students with "too much" 
information about the issue, which tends to unsettle them because it complicates the for/against, Republican/Democrat, conservative/liberal dualisms they had anticipated. I have found that bombarding students with this "tidal wave" of information is a productive starting point for a process intended to push them to see policy issues in more complex ways.

\section{Messy Mapping (5 Minutes)}

At the start of class, I distribute a one-page handout that includes (1) the exercise's three learning objectives; (2) brief explanations of the five steps involved in the exercise, outlined here; and (3) a chart of "elements to consider" (table 1). This chart facilitates the first step of the exercise, in which students individually brainstorm elements relevant to the policy issue by creating messy maps on scrap paper. Along with individual stakeholders, institutions, and events, the chart includes less-obvious elements such as norms, symbols, and dominant narratives. Students are instructed to think about the readings they completed and then brainstorm relevant elements and relationships. If they seem hesitant, I remind them that these initial maps are referred to as "messy" for a reason: "You can’t do it wrong!"

\section{Group Discussion (5 Minutes) and Mapping (15 Minutes)}

Students then discuss and compare their messy maps in groups and explore how they might be integrated into a more comprehensive picture of the policy issue. ${ }^{4}$ They next are prompted to create a group map that visually represents the most relevant elements and relationships of the policy issue. This involves debating what to include, imagining designs, and drawing on flipchart paper or dry-erase boards, if available. The instructions encourage students to 'Draw pictures, use shapes, arrows, words, anything you'd like. It's not an art contest...have fun with it!" Wandering around the classroom, I observe their progress, spur groups on with 
questions, and enjoy the energy of students teaching one another while actively engaging a complex issue.

Keeping students mindful of time can be challenging during this stage. To counteract the tendency of some groups to bypass discussion and delve into mapping, I take a few minutes to distribute the markers. If, conversely, groups have not transitioned from discussion to mapping after eight minutes or so, I suggest that they start drawing their ideas while continuing their conversation. When two minutes remain, I remind them that it is not possible to include everything. To keep students aware of time throughout the exercise, I project a large countdown timer on the screen, which heightens the energy in the classroom. ${ }^{5}$

\section{Gallery Walk (10 Minutes)}

When completed, the maps are displayed on whiteboards or, if on flipchart paper, taped to the walls. Students are reminded that maps are not self-explanatory but rather serve as a springboard for explanation and discussion. They then take part in a "gallery walk" to view other maps and ask questions. Two students from each group remain to present their map and answer questions, rotating every few minutes to give everyone an opportunity to walk the room. The primary purpose is for students to recognize that there are many different ways to explore the same policy topic; therefore, it is not a problem if they cannot view all of the maps. Along with observing the flow of students, I join the gallery walk, sometimes asking questions but mostly listening to students proudly discuss their maps with classmates.

\section{Closing Discussion (10 Minutes)}


The exercise ends with a class discussion. I prompt students with a mix of questions that ask them to articulate new understandings of the policy issue, as well as to metacognitively reflect on the critical-thinking process. These questions can vary but I keep them broad enough to allow students to influence the direction of our conversation. ${ }^{6}$ Admittedly, it is sometimes difficult for students to transition from the physically active portion of the exercise to the discussion. As a result, I have learned to avoid forcing too much into the final minutes and instead ensure that students leave with two or three clear takeaways from the experience.

As an active-learning exercise, situational mapping is designed to provoke students to recognize the complexity of policy issues and help them acclimate to the practice of thinking critically. Assessment is needed to measure its effectiveness in achieving these outcomes, but observation alone is enough for assurance that my students enjoy the process and learning from one another. No exercise can address every challenge in our classrooms; however, from small teaching can come small victories.

\section{NOTES}

${ }^{1}$ Examples of situational mapping that can be used to explore political concepts include prompting students to visually map the "American presidency" or "political polarization." For metacognitive reflection through mapping, students can be asked to visually represent the course syllabus or "effective exam preparation." I also use the exercise for leadership consulting with public officials by designing "ripped-from-the-headlines" prompts, such as "Evidence of a widespread sexting ring has emerged in local schools. Visually map the complex situation in which you must address this crisis." Each variation utilizes the same primary steps discussed here; only the starting prompts change. 
${ }^{2} \mathrm{CQ}$ Researcher reports, published by CQ Press, are a valuable resource for engaging publicpolicy issues in my course (available at http://library.cqpress.com/cqresearcher). If needed, I supplement these reports with news articles covering recent developments.

${ }^{3}$ Students complete 10 "pre-discussion" assignments during the semester, each worth $2 \%$ of their grade. The questions ask students to (1) identify and explain the policy issue's central components and debates, supported by specific evidence from the assigned readings; and (2) apply concepts recently covered in class to analyze the policy issue (e.g., "How can concepts associated with federalism help us make sense of the abortion issue?").

${ }^{4}$ Groups of four to six students seem best for encouraging a diverse range of ideas while still involving everyone. Whereas my courses typically have 30 to 35 students, I have used this exercise in settings with as many as 80 participants, keeping group sizes to around five. The only difference was that participants did not have enough time to view all of the maps during the gallery walk, which is not a problem. Therefore, although I have not had the opportunity to do so, theoretically there is no reason why mapping cannot be used in larger lecture classes, if space permits.

${ }^{5}$ Several countdown timers are available online. I typically use www.onlinestopwatch.com/countdown.

${ }^{6}$ Questions to prompt the closing discussion include What did you learn from this experience? What relationships among elements emerged from your mapping? What did you notice on other maps that was not reflected on your own? Why is this policy issue more complex than it appears? If you had views about this policy issue before today, how did they develop as a result 
of the exercise? What was the most challenging portion of today's exercise and why? Of course, these questions can be tailored to accomplish a wide range of learning goals.<end endnotes>

\section{REFERENCES}

$\checkmark$ American Association of Colleges \& Universities. 2009. "Critical Thinking VALUE Rubric."

Available at www.aacu.org/value/rubrics/critical-thinking.

$\checkmark$ Clarke, Adele E. 2003. "Situational Analyses: Grounded Theory Mapping after the Postmodern Turn.” Symbolic Interaction 26 (November): 553-76.

$\checkmark$ Clarke, Adele E., Carrie Friese, and Rachel S. Washburn. 2018. Situational Analysis:

Grounded Theory after the Interpretive Turn, second edition. Los Angeles: SAGE.

$\checkmark$ Keohane, Robert 0. 2009. "Political Science as a Vocation.” PS: Political Science \& Politics 42 (2): 359-63.

$\checkmark$ Lang, James M. 2016. Small Teaching: Everyday Lessons from the Science of Learning. San Francisco: Jossey-Bass.

Table 1 Elements to Consider (adapted from Clarke 2003, 564)

Individual human actors: key individuals in a situation, experience, personalities, etc.

Nonhuman elements: structured roles, laws, rules, norms, incentive structures, infrastructure, technologies, specialized information, etc.

Collective human elements/actors: particular groups, organizations, etc.

Implicated/silent actors: individuals and groups passively involved

Expectations: of actors, moral/ethical elements, mass media, popular culture, etc.

Political/economic elements: local/regional/national governments, industries, political parties, political ideologies, non-governmental organizations, politicized issues, etc. 
Sociocultural/symbolic elements: religion, race, sexuality, gender, ethnicity, nationality, class, and other influential symbols

Temporal elements: past history, crises, pre- or post-election, trajectory, etc.

Spatial elements: spaces in the situation, geography, local versus regional versus national, etc.

Other major issues/debates in the current public discourse

Dominant narratives or stories: regarding individual or collective human actors, and/or nonhuman elements: how these are variously perceived by others

Other kinds of elements? 